\title{
DYA KASSEMBE E A REPRESENTAÇÃO DAS VOZES DE MULHERES ANGOLANAS
}

\author{
Rosana Baú Rabello (USP)
}

Resumo: Dya Kassembe é uma escritora angolana ainda pouco conhecida na academia brasileira, mas que possui uma produção literária e ensaística expressiva. Com livros publicados na França e em Angola, desenvolve um trabalho bastante voltado à discussão da experiência de vida das mulheres angolanas, do seu lugar na sociedade, na história e na escrita. Neste artigo, fazemos uma rápida apresentação da obra da escritora e desenvolvemos uma leitura crítica de seu livro Cartas para maridos temerários, pensando nas estratégias de representação das mulheres.

Palavras-chave: Dya Kassembe; Mulheres; Feminismos; Angola.

Abstract: Dya Kassembe is an Angolan writer who has an expressive literary and essay writing. With books published in France and Angola, she develops a work that is very focused on discussing women's life experiences, place in society, in history and in writing. In this article, we make a brief presentation of her production and develop a critical reading of her book Cartas para maridos temerários, thinking about literary strategies for women representation.

Keywords: Dya Kassembe; Women; Feminism; Angola.

\section{DYA KASEMBE, DYA KASSEMBE OU DIA KASSEMBE ${ }^{1}$}

Dya Kasembe é o pseudônimo literário de Amélia de Fátima Cardoso. Nascida em 1946, em Muxima, na localidade de Mumbondo-Muxima, na província do Bengo, revela uma grande estima pelas mulheres que compuseram o sobado

1 As várias grafias do nome aparecem impressas em suas diversas publicações realizadas em Angola e na França, assim como nas traduções para o inglês e para o alemão de seu livro As mulheres honradas e insubmissas de Angola. 
dessa região e as homenageia em seu livro As mulheres honradas e insubmissas de Angola (2010). Em entrevista concedida ao Fair Play, programa de entrevistas da televisão angolana², a escritora revela ser neta de Bamba Kasembe, um grande soba da região que vai do Dondo, Kwanza-Norte, ao Amboim, Kwanza-Sul, em uma região que não foi dividida na partilha da África negociada pela Conferência de Berlim.

Sua carreira de escritora iniciou-se com publicação de poemas e contos nos jornais da época colonial, nos quais assumia os pseudônimos de Ivi, Liana e AFC. Sua primeira publicação em livro é Angola, 20 ans de guerre civile: uma femme accuse (1995). Ele foi escrito e publicado na França pela editora L'Harmattan, pois a autora viveu mais de vinte anos no país onde atuou como enfermeira e realizou sua graduação e mestrado em filosofia pela Universidade de S. Dennis, Paris 8.

No livro, começa por apresentar um histórico da condição colonial anterior à guerra, identificando alguns dos aspectos que permearam o embuste da política portuguesa de assimilação, a segregação dos negros nos diferentes bairros e musseques de Luanda e a exploração do trabalho forçado. Também problematiza a violência à qual as mulheres muitas vezes eram submetidas para que houvesse a mestiçagem,

2 Acessível em https://www.youtube.com/watch?v=wnuEVS8OPJA 
confrontando o entendimento de que existia uma única pátria, com províncias ultramarinas, onde todos teriam o estatuto de cidadãos portugueses e eram igualmente respeitados como tais. A autora traça ainda um histórico da luta de libertação e dos movimentos que se mobilizaram para desenvolvê-la (MPLA, UPA e FNLA), assim como o papel de seus líderes Agostinho Neto, Jonas Savimbi e Holden Roberto, respectivamente. Os movimentos de libertação de Angola não conseguiram a unificação de seus esforços, o que fez com que a Frente Nacional de Libertação de Angola (FNLA), o MPLA e a União Nacional para Independência Total de Angola (Unita) lutassem contra os portugueses, mas também entre si. Houve assim uma intensa e complexa disputa no vasto campo do nacionalismo angolano.

Depois do 25 de abril de 1974, a autora apresenta um calendário dos eventos que antecedem e os que procedem o Acordo de Alvor, assinado entre o governo português e os principais movimentos de libertação, estabelecendo os parâmetros para a partilha do poder entre os grupos.

Em um anexo, ao final do livro, apresenta-se a enunciação feminina registrada no título "une femme acuse", no qual a autora registra, em primeira pessoa, suas impressões ao retornar a Angola, em 1993, em um intervalo da guerra 
civil que ainda perduraria até 2002. Registra as percepções da chegada ao aeroporto, das conversas com crianças e mulheres nas ruas de Luanda, das limitações que a televisão apresenta para informar e formar criticamente, da saúde, da educação e da luta cotidiana da população comum para contornar as contingências das dificuldades e do abandono promovidos pelos longos anos de guerra.

Em 1997, Dya Kasembe publica Femmes sacrées, insomises e Rebelles. O livro também foi traduzido e publicado em 2005 pela editora Mayamba, em Angola. Segundo a autora, contrariando sua intenção inicial, o trabalho foi classificado como uma obra de sociologia, pois é organizado a partir dos relatos e das memórias sobre a tradição das mulheres de Kisama, antigo sobado da região que se estendia por um grande território do Kwanza Norte ao Kwanza Sul. Segundo Kasembe (2005, p.20), sendo ela poeta, a sua intenção foi recitar essas memórias e relatos para transmitir o que lhe foi legado.

O livro é um testemunho que fala dos tipos de mulheres da Angola pré-colonial, do processo de aprendizado que elas vivenciavam com as mais velhas e das estratégias que encontravam para, a partir do espaço que a tradição Ihes conferia, construírem sua autonomia e sua valorização social. 
Fala também do período colonial e do processo de mudança no modo de vida dessas mulheres, violentadas, deportadas, instaladas em vilas e submetidas às consequências políticas da assimilação e do "branqueamento", desenvolvido por Portugal.

As mulheres honradas e insubmissas de Angola apresenta uma autora com postura incisiva sobre a necessidade de recuperar a própria história para fortalecer a identidade e promover a autonomia:

Com Angola independente, cabenos o inegável direito de restaurar de forma incisiva a nossa identidade histórica e cultural, fundada na honestidade intelectual, de pôr em dúvida e de contestar, para corrigir o que erradamente foi escrito, de maneira que o mundo saiba o que fomos, o que somos e deduza o que seremos ou estamos em via de ser. (KASEMBE, 2005, p.15)

Assim, Dya Kasembe não somente desenvolve sua crítica à opressão vivenciada pela mulher angolana, mas também ao jugo colonial exercido contra seu povo. Sua concepção de resistência e insubmissão femininas colocam problemáticas que vão além da conquista de direitos civis pelas mulheres. O imperialismo, o neocolonialismo, as ditaduras, o racismo, o machismo, dentre outras formas de opressão, intersectamse e acabam por demonstrar que o feminismo, isoladamente, não é capaz de reagir à teia que esses elementos configuram. 
No continente africano, a compreensão feminista das relações de opressão dialoga, em algumas de suas expressões, com a abordagem interseccional e, de maneira geral, assim como as demais expressões do feminismo, não dissocia teoria, vivência e militância. Na compreensão da escritora e acadêmica nigeriana, Amina Mama (s/d), por exemplo, a teoria feminista sempre deriva da política e as perspectivas dessa teoria implicam novas maneiras de entender a experiência de conflitos, as contradições e novas maneiras de atuar no mundo. A pesquisadora, em seu livro Beyond the masks (s/d), teoriza sobre o feminismo e a configuração da subjetividade feminina, considerando o fato de que o psicológico e o social não são dissociáveis e entendendo que raça, gênero, classe e localização geográfica são elementos essenciais para sua constituição.

As vozes femininas em diferentes países africanos mostram-se, cada vez mais, como importante campo de luta e resistência, assim como se apresentam como um contraponto ao imperialismo o qual pode estar conectado também ao feminismo ocidental quando esse se baseia no pensamento liberal e enfatiza as divisões de gênero como razão exclusiva para a opressão das mulheres. Essa abordagem feminista pode assimilar os padrões eurocêntricos de equidade se não considerar as formas de opressão que intersectam 
as opressões de gênero, raça e classe social, assim como de etnicidade, nacionalidade, geração e composição de diferentes experiências, contornadas pelo contexto histórico, político, econômico e cultural que enquadra as diferenças e produz formas particulares de discurso e ação social. Em seu livro, Dya Kasembe apresenta interpretações que consideram essa face interseccional do feminismo e busca entender a dominação masculina no contexto do colonialismo, da sociedade de Kisama e, posteriormente, de Angola contemporânea.

As mulheres honradas e insubmissas possui três capítulos, sendo que o primeiro se propõe contar vários aspectos da tradição da região de Kasembe - "emirato" de Kisama. Dya Kasembe utiliza o termo emirato, pois, segundo ela, há aproximações possíveis entre o sobado e os emiratos do Oriente Médio no que diz respeito à sua extensão e à organização de seus domínios. Além disso, a autora acha a aproximação apropriada em termos de uma consciência que procura se descolonizar e tirar do centro referências às definições europeias (KASEMBE, 2010).

Ainda nessa primeira parte da obra, são apresentados, de maneira detalhada, rituais da tradição do grande sobado de Kasembe, mais especificamente, aqueles que incidem 
sobre a mulher. A autora ressalta o importante papel das mulheres ao longo das várias etapas da vida (desde a infância até a velhice). Também apresenta bastante destaque para a liderança, para a valorização e para a união das mulheres, vivenciadas a partir dos desdobramentos da relação delas com a tradição da qual descendem. Essas mulheres estavam inscritas em um processo que ia do aprendizado do prazer para si e para seu possível futuro companheiro ${ }^{3}$, ao aprendizado da partilha de seus afetos para conviver em um lar polígamo.

Dya Kasembe ressalta que havia acomodações sofridas pela tradição e que eram proporcionadas, muitas vezes, pela reação e negociação dessas mulheres para alterarem alguns dos espaços nos quais estavam inscritas. Fala, por exemplo, da resistência à poligamia, sendo que essa não se refere à colonização católica, mas a uma percepção anterior à essa influência religiosa que controlava e reprovava muitos dos aspectos da organização social autóctone:

Em Kasembe, a poligamia deixou de ser praticada muito antes da chegada dos portugueses. As educadoras tudo fizeram para acabar com esse costume. Foi com base na experiência que elas

3 Na nossa cultura de origem, a menina era iniciada, ela sabia como ter relações sexuais, como dar prazer ao parceiro e a ela própria, assim como ela sabia como se sentir prazer com o parceiro sem penetração vaginal. Em suma, o sexo nunca foi tabu, antes da chegada da religião e, no caso de Angola, do Cristianismo. (KASEMBE, 2005, p.42) 
tinham concluído que um lar era mais estável quando havia uma só mulher e todos os filhos fossem de uma só mãe. (KASEMBE, 2005, p.46)

Como o afirma Amina Mama (s/d), de forma enviesada, maniqueísta e dualista, é, por vezes, entendido que os contextos africanos, antes da ocupação colonial, eram fixos ou estáticos. Contudo, havia constantes mudanças e trocas, como o explicita Kasembe em relação à resistência à poligamia. Nesse sentido, o feminismo conforme abordado pela autora apresenta múltiplas formas enraizadas em lutas que antecedem e podem, portanto, transcender as estruturas dos Estados Modernos.

Ainda no primeiro capítulo de As mulheres honradas e insubmissas de Angola, Dya Kasembe também observa a importante representação das mulheres de Kissama no Conselho dos Sábios. Esse conselho era chamado de Nganda, que deriva de Ngana, cujo significado é excelência. Era um espaço de reunião dos sábios para discutirem assuntos do reinado. "Entremos nesse local de sabedoria: trata-se de uma assembleia composta por homens e mulheres que, ao longo dos anos, acumularam bagagem intelectual e experiências que desejavam transmitir e utilizar para uma melhor qualidade de vida" (KASEMBE, 2010, p.61). 
Para falar desse conselho de sábios, Dya Kasembe chama atenção para o fato de que os critérios para admissão na Nganda eram os mesmos para homens e mulheres, sendo estes a idade, a experiência de vida, o poder de reflexão, a imparcialidade dos julgamentos, o fato de serem cultos espiritualmente.

Embora a autora apresente uma imagem essencialista da mulher, observa que havia uma especial valorização de sua experiência e que a misoginia não era praticada dentro do conselho:

A misoginia nunca teve lugar na Nganda, e a mulher ocupava um lugar de destaque que lhe conferia a própria natureza de mãe da humanidade, com uma intuição profunda e cautelosa que não possuía o homem guerreiro e impulsivo. Ela era considerada como portadora da paz e da união. O poder de decisão cabia à mulher. Pode-se aqui avaliar a importância que ela tinha na sociedade (KASEMBE, 2010, p.61)

Na segunda parte do livro, a autora fala do processo de novas configurações a partir da colonização, da escolarização e dos novos contextos de opressão e de lutas sociais às quais as mulheres estavam expostas. A última parte é votada a "catalogar" um conjunto de situações sociais às quais as mulheres angolanas estão expostas, por exemplo: mulheres que deixam o campo e não encontram 
estruturas de acolhimento nas cidades; outras que, tendo alguma autonomia financeira, passam a ser espoliadas pelos companheiros; aquelas que assumem as responsabilidades de casa, filhos e sustento sozinhas, sem amparo e com absoluta falta de recursos; aquelas que conseguem conquistar autonomia financeira e independência; ou aquelas que são camponesas, "convertidas em operárias agrícolas, trabalhando para alimentar o mercado de exportação" (KASEMBE, 2010, p.104).

Em 1999, é publicado ainda outro livro de Kasembe, Soigner em Noir et Blanc, o qual conta um pouco de sua experiência como enfermeira e mulher negra em Paris. Em 2006, publica Os Amores da Sanzala, pela editora Nzila. Essa é uma obra que expõe a posição da autora sobre as relações entre o branco colonizador e as mulheres autóctones através de contos. O livro reúne seis histórias expondo cotidianos de opressão vivenciados pelas mulheres negras que são subjugadas em suas relações com os homens brancos.

Os contos possibilitam a reflexão de diferentes opressões sofridas pelas mulheres durante o colonialismo: a opressão do sistema colonial, da desigualdade social e do patriarcalismo que se intersectam e impedem a construção de uma relação equânime. As narrativas destacam essa tripla opressão. As 
histórias se aproximam de algumas das reflexões de Frantz Fanon sobre a relação entre colono e colonizado e sobre a consolidação do amor em relacionamentos inter-raciais. Para ele: "nas relações entre a mulher de cor e o europeu, trata-se de determinar em que medida o amor autêntico permanecerá impossível enquanto não eliminarmos este sentimento de inferioridade [...]" (FANON, 2008, p.54). Por meio de seus contos, Kasembe chama atenção para essa falta de reciprocidade e equivalência entre as partes nos relacionamentos inter-raciais em contextos de colonização.

Em 2007, é publicado o livro de Cartas para maridos temerários, uma reunião de 88 cartas que mimetizam a voz de mulheres que endereçam reclamações, recados e pedidos para seus companheiros. O livro se dedica a compor um painel de mulheres de muitas idades e condições sociais que se encontram em situação de abandono, de sofrimento causado pela traição, de insegurança e de decepção, além de diversas histórias de violência e relações abusivas.

Na introdução de seu livro, Dya Kasembe revela que cada umas das cartas apresentam histórias imaginadas por ela. Contudo, na entrevista que concedeu à televisão angolana ${ }^{4}$, diz ter recolhido histórias ao longo de alguns anos de conversa com mulheres às quais encontrou em feiras, praças, ônibus e

4 Acessível em https://www.youtube.com/watch?v=wnuEVS8OPJA 
indagou sobre as cartas e recados que pretendiam endereçar aos companheiros.

Essa também é a premissa do livro publicado em 2014. A autora recolhe depoimentos que organiza em Cartas, recados e desabafos, agora com diferentes remetentes: filhos que escrevem para seus pais ou mães; mães ou pais que escrevem para seus filhos e maridos que escrevem para suas esposas. Também são essas relações bastante pautadas pelo parentesco e pela reprodução de lugares comuns dessas relações.

A autora também desenvolveu um processo de recolha e divulgação de depoimentos de mulheres angolanas relatando suas expectativas com o período de paz que procedeu tantos anos de guerra de libertação e outros tantos de guerra civil. O projeto foi desenvolvido conjuntamente com a escritora moçambicana Paulina Chiziane e foi publicado em 2008 com o título O livro da paz da mulher angolana: heroínas sem nome. O livro contém narrativas de mulheres angolanas sobreviventes dos conflitos e inclui fotografias feitas durante a execução do projeto.

Margarida Paredes (2017) comenta sobre a importância do projeto de construção desse livro: "Este projeto é nobre e inscreve na memória coletiva e na História de Angola, 
Heroínas sem Nome, atores periféricos cujas experiências de vida são quase sempre silenciadas pelo discurso dominante da História" (vale dizer que esse silenciamento ocorre mesmo em tempos de paz construídos oficialmente pela MPLA).

O livro se coloca, portanto, como uma interessante proposta de fazer reverberar essa voz de mulheres silenciadas que, ao falarem do período de paz, não deixam de referenciar a época da guerra; as marcas e espaços de luta que empreenderam, mesmo que, até então, não houvesse registro de sua resistência e importantes enfrentamentos.

Como vimos, o trabalho de escrita de Dya Kasembe é bastante diverso no que diz respeito aos gêneros de escrita, mas sempre ancorado pela perspectiva e pela observação da mulher localizada histórico e socialmente. A autora procura sempre tecer diálogos em que possa explorar a enunciação do ponto de vista do sujeito feminino, reconhecidamente marginalizado e excluído.

\section{CARTAS PARA MARIDOS TEMERÁRIOS: INTERLOCUÇÕES POSSÍVEIS E CONSTRUÇÃO DO DISCURSO CONTRA A VIOLÊNCIA E O ABUSO MASCULINOS}

Cartas para maridos temerários (2007) é um livro singular. Nele, a escritora Dya Kasembe reúne 88 relatos em forma de cartas onde mimetiza a voz de mulheres que reclamam de 
suas relações com os companheiros, namorados, maridos, amantes ou parceiros sexuais. Nesse trabalho, a escritora retrata temas da intimidade e do caseiro, encenando, ainda que sob uma escrita ficcional, um modo de vida comum das mulheres angolanas na atualidade. A trama ficcional tem como ponto de partida as vivências conjugais e acaba por compor um painel de mulheres de muitas idades e condições sociais que, contudo, compartilham de situações de traição, abandono, violência e abuso.

É essa mescla entre a recolha de histórias e a sua encenação que confere um tom peculiar à escrita desse livro. Aqui, estamos no campo do comum: os dramas vivenciados pelas mulheres em sua vida simples, cotidiana. Contudo, essa simplicidade e quotidianidade não escondem o complexo das relações e das estruturas sociais que os discursos ficcionalizados dessas mulheres acabam por apresentar. Entre encontros e desencontros, entre desejos e traições, entre uniões e rompimentos, acompanhamos esses fragmentos de histórias que giram em torno da hegemonia masculina e da manutenção de privilégios concedidos aos homens nas relações.

Esses privilégios e essa hegemonia estão conectados à opressão construída sobre um corpo específico, feito refém 
culturalmente e que recebe, desde os primeiros momentos de vida, uma educação que o secundariza. Beauvoir, em $O$ segundo sexo, explicita que:

Todo indivíduo que se preocupa em justificar sua existência a sente como uma necessidade indefinida de se transcender. Ora, o que define de maneira singular a situação da mulher é que, sendo, como todo ser humano, uma liberdade autônoma, descobre-se e escolhe-se num mundo em que os homens lhe impõem a condição do Outro. Pretende-se torná-la objeto, votá-la à imanência, porquanto sua transcendência será perpetuamente transcendida por outra consciência essencial e soberana. $\mathrm{O}$ drama da mulher é esse conflito entre a reivindicação fundamental de todo sujeito, que se põe sempre como o essencial, e as exigências de uma situação que a constitui como inessencial. Como pode realizar-se um ser humano dentro da condição feminina? (BEAUVOIR, 2016, p.23)

Aponta, assim, tanto a opressão que pesa sobre as mulheres, quanto as dificuldades de se desvencilharem dos nós que as prendem a tal servidão. Beauvoir entende que as mulheres assumiram, ao longo da história, o lugar do Outro, da pura alteridade, cuja identidade é determinada pelo homem. Essa compreensão e essa construção cultural não oferecem muitos espaços para que se internalizem 
valores diferentes, pois as mulheres se veem envolvidas em um sistema de inferiorização que as impele a servir sexual, emocional, moral e financeiramente, sendo necessário um processo de desconstrução.

Cartas para maridos temerários acaba por promover uma reunião de textos que pretendem registrar os anseios e as decepções femininas com as relações amorosas que, de diversas maneiras, refletem os privilégios masculinos nessas uniões sempre assimétricas, desiguais. O habitual e o rotineiro da vida dessas mulheres e homens apresentam um interessante registro dessas assimetrias e desigualdades.

As cartas articulam situações e reações cujo retrato pretende se aproximar efetivamente daquilo que poderiam ser os recados e desabafos de mulheres simples ou estudadas, de mães, esposas ou amantes que se comunicam abertamente com seus parceiros. São composições de fácil compreensão, despretensiosas e bastante singelas, como seriam as composições dessas mulheres que querem deixar muito claro o que as incomoda e, por vezes, proporem soluções para os imbróglios do dia a dia. A carta de Mariquinhas para Zeca pode servir como exemplo desse registro:

Zeca,

É mesmo verdade que eu bebo, e já bebia quando me conheceste, mas não bebo 
com o teu dinheiro. Isto não é motivo para bateres sempre na mesma tecla, que uma mulher não deve beber assim. Não sou a primeira nem a última, eu tenho razões para beber mas tu não tens razões para disparatar e bater, porque quando bebo até nem faço confusão. Danço, faço amor contigo, fico quente, e tu gostas não é? Sobretudo quando bebo champanhe fico com aqueles olhos que nem consegues resistir? Então amor, já me conheceste assim e serei sempre assim. Diga-se de passagem amor, que também não bebo por aí além. $E$ também nem bebo todos os dias.

Eu fui militar das FAPLA, e só sei pegar numa metralhadora; eu só não te bato porque tenho medo de te matar assim como estás todo magrinho e até uma ventania poderia carregar, se te der um empurrão vais mesmo cair. Eu bebo, mas tu fumas, e não fumas tabaco, ou pensas que não sei. Nem eu nem tu temos filhos, entregámos a vida toda à revolução, então deixa-me em paz. Tu fumas e eu bebo, qual é o mal?

A tal pensão dos antigos combatentes, nem chega para eu afogar as minhas mágoas e ainda achas que gasto muito na bebida! Bebo sim senhor, e como sei que se te disser isto na cara vais me matar, digo-te por escrito porque ainda sei escrever. E se tu não bebes, então deverias arranjar outra mulher que não beba, porquê estás agarrado a mim? Então é porque me amas. Então amorzinho, bebo sim senhor, e não 
hei-de beber por quê? Sabes porque te escrevo amor? Para te dizer QUE BEBO, BEBI E BEBEREI.

Mas eu amo-te mesmo assim, e sei que tu me amas e muito mesmo. Não me compliques a vida Zeca, o tempo que nos resta vamos ficar em paz. Vivermos bem, comermos bem, termos um conforto. Para quem vamos guardar o dinheiro, não temos herdeiros, e também nem temos sobrinhos? Por isso, beber de vez em quando, quando temos dinheiro, não é mal para ninguém. Os vizinhos não têm queixas nossas. Sempre tua, Mariquinhas. (KASEMBE, 2007, p.120121)

Todas as cartas aparecem acompanhadas das referências de profissão e idade dos seus remetentes e destinatários. No caso de Zeca e Mariquinhas, há o registro de que ele tem 68 anos e é general na reserva e de que ela tem 48 anos e é exmilitar das FAPLA.

A utilização das cartas como estratégia para a composição dessas personagens imita a espontaneidade, intimidade e naturalidade que esse gênero expressa. Dessa forma, toma o leitor por confidente, o qual vê-se inserido nesse processo de interlocução que o aproxima das mulheres representadas. Segundo Andrée Crabbré Rocha (1965, p.13):

A carta é um meio de comunicar por escrito com o semelhante. Compartilhado por todos os homens, quer sejam ou 
não escritores, corresponde a uma necessidade profunda do ser humano. Communicare não implica apenas uma intenção noticiosa: significa ainda "pôr em comum", "comungar". Lição de fraternidade, em que as palavras substituem atos ou gestos, vale no plano afetivo como no plano espiritual, e participa, embrionária ou pujantemente, do mecanismo íntimo da literatura dádiva generosa e apelo desesperado, ao mesmo tempo.

Dya Kassembe explora esse potencial das epístolas e articula um registro que se traveste como documentário. Há a escolha, por parte da autora, de alguns retratos de mulher, sempre figurados pela ligação amorosa e por alguma dependência relativamente ao homem: seja dentro do casamento, de relacionamentos fortuitos, de namoros ou de casos extraconjugais.

A invenção de um método de narrar e de uma forma de olhar e registrar essas relações passa pela construção de um excedente que nos permite observar as situações dispostas pela autora e avaliar a posição dessas mulheres quanto ao seu lugar social e à representação discursiva que se faz desse lugar. O registro das cartas permite identificar que, mesmo projetando sua voz por meio das cartas, as mulheres posicionam-se como face complementar e dependente da 
relação com o homem, sendo essa uma percepção que passa pela construção tanto dos temas quanto da forma ${ }^{5}$.

Entendemos que as cartas não deixam de manter-se como registro circunscrito ao espaço de representações da mulher como Outro, sem romper ainda com um lugar de fala instituído pela dominação do homem. Para Beauvoir:

O homem que constitui a mulher como um Outro encontrará, nela, profundas cumplicidades. Assim, a mulher não se reivindica como sujeito porque não possui os meios concretos para tanto, porque sente o laço necessário que a prende ao homem sem reclamar a reciprocidade dele, e porque, muitas vezes, se compraz no seu papel de Outro. (2016, p.18)

Nas cartas, as mulheres, mesmo como autoras das missivas, continuam se definindo em relação ao homem, considerando sua função dentro do mundo masculino e das relações familiares e conjugais.

Não estamos a desmerecer a produção das cartas escritas por Dya Kasembe, pois entendemos seu lugar de importância como interlocutora das mulheres e como autora que pensa a representação feminina em um contexto de denúncia da

5 A construção discursiva das cartas mantém-se dentro do registro dos termos instituídos pela lógica e razão masculinas. É um lugar de fala marcado pela identificação de padrões considerados próprios do gênero, garantindo a pertinência imaginária das pertenças aos grupos dos homens e das mulheres (KEHL, 2016, p.11) 
violência, abuso e subordinação da mulher. Se sua escrita acaba por reproduzir no seu registro literário esse lugar instituído pela relação de hierarquia e antagonismo que circunscreve homens e mulheres em seus lugares cultural e socialmente construídos, esse também se apresenta como um instrumento importante para debate.

Nas denúncias que faz, por exemplo, apresentam-se as distintas oportunidades e formas de tratamento quanto ao valor do trabalho e do conhecimento das mulheres. Angélica, de 52 anos, funcionária pública, com formação apenas até a sétima classe, ressente-se do marido que, também funcionário, desmerece sua capacidade e inteligência: "[...] é a vez de tomar a palavra junto de ti, dos teus amigos e da tua família, junto mesmo dos nossos filhos que me consideram uma mulher apagada e sem voz, e além do mais, inculta, como sempre me trataste diante deles" (KASEMBE, 2007, p.17). Também fala da violência representada pela agressão física, imagem recorrente em outras tantas cartas apresentadas no livro, como a da estudante do ensino médio, Joana, de 27 anos, casada com um policial que a agride. Também de Manuela, professora de história de 30 anos, casada com um líder político, assim como da zungueira Berta, a qual sustenta o lar sozinha e é casada com um antigo soldado 
desempregado que a maltrata e violenta e contra quem já fez queixa na OMA (Organização da Mulher Angolana).

A grande maioria das cartas fala de traição e da dissolução do lar, assim como da humilhação e do sofrimento causados pela situação. Algumas das mulheres traídas não conseguiriam se reestruturar financeiramente sem a ajuda de um companheiro, pois não têm uma condição financeira que lhes permite isso ou precisam preocupar-se com os filhos quando se veem abandonadas. Outras mulheres retratadas nas cartas têm casa construída por elas mesmas, trabalhos que Ihes asseguram algum espaço de autonomia, além de serem, muitas vezes, únicas provedoras da casa. Esse é o caso de Augusta que vive de pequenos bicos e se desdobra para sustentar a casa, continuar estudando e cuidar dos filhos. O marido, um ex-soldado desempregado, usufrui do pouco que eles têm e ainda a trai. A carta que Augusta escreve é uma ameaça e um rompimento: "[...] já temos dois filhos e ainda queres mais um. O terceiro de certeza que não será teu" (KASEMBE, 2007, p.41).

Filó, uma jurista de 57 anos, também se ressente de ter ajudado o marido a construir uma carreira e estudar, sendo ela, durante muitos anos, quem sustentou sozinha o lar. A carta que endereça ao marido também é uma 
ameaça de término que expressa o sofrimento pela falta de reciprocidade que ele demonstra agora que conquistou uma melhor posição e novas relações:

Quiseste pôr-me no passeio sabendo que a única casa que possuo é esta onde estamos. No entanto tu tens casas e apartamentos e uma das vivendas ofereceste à tua segunda básica, muito mais inteligente do que eu, que conseguiu convencer-te a dares-Ihe casa e carro (KASEMBE, 2007, p.25)

Outras tantas cartas falam do ciúme e dos obstáculos que os esposos ou mesmo os filhos impõem ao estudo e à formação. Tita, mulher de 30 anos, sem profissão e tendo estudado somente até a $9^{a}$ classe, enfrenta essa dificuldade provocada pelos ciúmes: "Tentei recomeçar a estudar; mas na tua mente o meu único desejo que me levava a estudar é de seduzir os professores e fornicar com todos eles" (KASEMBE, 2007, p.23). Mariana, de 23 anos, estudante da $8^{a}$ classe também se defronta com barreiras para que possa estudar, sendo essas impostas pela sua condição de gênero. A gravidez e a necessidade de ajudar com o sustento da casa a impediram de continuar os estudos. Passado o período mais crítico de problemas financeiros e cuidados com o bebê, o que a impediria de continuar era o ultimato do marido, agente de segurança, que exigia a 
esposa no lar, a cuidar das obrigações domésticas. A carta de Mariana é uma justificativa dos motivos que a fizeram abandonar o lar e retornar à casa dos pais: "Tentei ser razoável contigo, fiz proposições de deixar as refeições do dia já preparadas. Pois bem, quando te decidires, estarei lá onde me encontraste. Isto é: na casa de meus pais e a estudar" (KASEMBE, 2007, p.27).

Além dessas histórias citadas, Cartas para maridos temerários apresenta outra porção de situações que compõem um panorama da vida conjugal e social das mulheres de Angola. Para a autora, na conclusão do livro, o que ela faz é uma recolha de histórias que podem servir de exemplo e estudo: "Neste livro, nós não analisamos, expomos o que encontramos no seu estado bruto. Nos meus trabalhos, retrato a vida da maioria desconhecida e da minoria conhecida" (KASEMBE, 2007, p.188).

\section{CARTAS PARA MARIDOS TEMERÁRIOS: REIVINDICAÇÕES FEMININAS COMO DISCURSO}

É inegável que o discurso das mulheres é historicamente marginalizado. Assim, a insistência em sua produção e a resistência que ela representa são importantíssimas na construção de um contradiscurso. Nesse sentido, é interessante ressaltar a relevância do discurso feminino na 
construção de uma epistemologia permeada pelas relações de gênero, raça e classe e pela politização do corpo, assim como pela compreensão da dimensão política do cotidiano, das relações, do diálogo e da vida privada.

Nas cartas produzidas por Dya Kasembe, fala-se das questões que envolvem o feminino na sua representação como mães, esposas, donas de casa, amantes. Esses são os papeis sociais que acabam por definir a imagem dessas mulheres, assim como passam a encaminhar o seu registro ficcional e determinar a interação com os homens. Dá-se, assim, uma atenção especial à história social dessas mulheres a partir de seus contextos concretos, situados na esfera da vida privada.

Esse não é um espaço de discussão desimportante na construção do discurso feminista. Um dos mais significativos insights do pensamento feminista é a frase de efeito criada por Carol Hanisch em que ela diz que "o pessoal é político" (BIROLLI, 2014, p.35). Esse slogan chama atenção para que as mulheres estejam juntas para compartilhar experiências e descobrir que muitos dos aspectos problemáticos de suas vidas pessoais são característicos da vida de outras mulheres, sendo que isso não é fruto de circunstâncias individuais ou questões pessoais, mas são configurações sociais que se 
apresentam opressivas para as mulheres, especificadas e localizadas historicamente.

Com a conquista social da mulher, é possível vislumbrar a presença de um eu-feminino delineando-se, sendo capaz de ver-se na ideologia e fora desta, em um movimento de construção que une a Mulher (abstração cultural) às mulheres em suas várias relações sociais diferenciadas. (SACRAMENTO, 2004, p.99)

Ressalvada a importância político-social da expressão literária representada pelas cartas escritas por Dya Kasembe, é essencial pensá-las enquanto forma de uma escrita feminina, assim como pensar seu diálogo com a construção de um discurso hegemônico masculino.

\section{CRIAÇÃO E MIMETISMOS}

Na composição das cartas apresentadas no livro Cartas para maridos temerários, existem regras visíveis e também uma escuta, uma disposição em acolher o ritmo daquelas vidas ali representadas. Há um encontro entre as escolhas éticas e estéticas da autora e os afetos presentes no funcionamento concreto do mundo. Nesse encontro, o dispositivo da escrita não apenas dá voz às mulheres, mas também encena essas vozes, construindo formas do artifício de invenção dessa escuta. É nesse sentido que as cartas apresentam um processo de criação. 
Isso ocorre porque, por mais que a autora possa efetivamente ter feito a recolha dessas histórias, reclamações e recados, ou, como ela mesma o diz, "exposto o que encontrou em estado bruto", ela recria esses registros e os inscreve na composição de um livro. Essa composição literária das cartas acaba por projetar a construção de um mimetismo, pois consiste na imitação que espelha os mecanismos de dominação masculina nas relações conjugais, apresentando a mulher emoldurada pelo contexto de algum tipo de dependência em relação ao homem: seja da proteção, da afetividade, da fidelidade, da ajuda financeira ou do compromisso com os filhos.

Na natureza, o mimetismo é uma imitação da cor ou da forma do ambiente, tendo essa imitação um caráter defensivo, agressivo ou de construção de uma identidade que dialogue com o ambiente. É no sentido de melhor se adaptar ao ambiente, repetindo algumas das características do próprio ambiente como forma de proteção ou de adequação, que o mimetismo se dá (NASCIMENTO, 2009). No caso das mulheres representadas nas cartas, elas definem-se dentro desse ambiente das relações conjugais, demonstram querer ajustar-se ao que se espera delas dentro dessa esfera, mas discursam contra aquilo que consideram abusos e contra o 
que as afeta dentro do que pode ser considerado aceitável ou não nesse espaço social do casamento.

Elas dialogam com uma imagem e com uma linguagem articuladas aos lugares instituídos para mulheres e homens, evocam esses lugares e encenam seus papeis estabelecidos socialmente, revelando aspectos ligados à "dominação masculina". A expressão é utilizada por Pierre Bourdieu, em livro homônimo, a partir do qual ele observa como a estrutura de dominação que privilegia o homem está incrustrada no pensamento, no comportamento e na linguagem dos indivíduos, fazendo com que a reprodução da ordem social seja mantida e legitimada:

A primazia universalmente concedida aos homens se afirma na objetividade de estruturas sociais e de atividades produtivas e reprodutivas, baseadas em uma divisão sexual do trabalho de produção e de reprodução biológica e social, que confere aos homens a melhor parte, bem como nos esquemas imanentes a todos os habitus moldados por tais condições, portanto objetivamente concordes, eles funcionam como matrizes das percepções, dos pensamentos e das ações de todos os membros da sociedade, como transcendentais históricos que, sendo universalmente partilhados, impõemse a cada agente como transcendentes. Por conseguinte, a representação 
androcêntrica da reprodução biológica e da reprodução social se vê investida da objetividade do senso comum, visto como senso prático, dóxico, sobre o sentido das práticas. E as próprias mulheres aplicam a toda a realidade e, particularmente, às relações de poder em que se veem envolvidas, esquemas de pensamento que são produto da incorporação dessas relações de poder e que se expressam nas oposições fundantes da ordem simbólica. Por conseguinte, seus atos de conhecimento são, exatamente por isso, atos de reconhecimento prático, de adesão dóxica, crença que não tem que se pensar e se afirmar como tal e que "faz", de certo modo, a violência simbólica que ela sofre. (BOURDIEU, 2002, p.62)

Por isso, falamos do mimetismo. Pois o caráter defensivo ou agressivo das reclamações e proposições que as mulheres fazem nas Cartas para maridos temerários não as arranca da identidade concebida pela estrutura opressora que regula o lugar social imposto às mulheres.

Esse status de inferioridade da mulher e de supremacia masculina não é superado por meio das declarações, reclamações e reivindicações dessas mulheres, pois as vontades expressas ainda estão conformadas ao campo da ordem estabelecida, configuram-se dentro dos termos dessa ordem, mimetizam-na. Todas as histórias se estruturam a partir da relação binária e assimétrica entre homem e 
mulher, nas quais essa, mesmo projetando sua voz por meio das cartas, posiciona-se como face complementar e dependente da relação com o homem. As remetentes das cartas acabam por expressar a relação de hierarquia e antagonismo por meio das quais mulheres e homens são histórica e socialmente constituídos. As vontades individuais dessas mulheres acabam por transitar nos limites das subjetividades 6 e carecem de um longo processo histórico para uma efetiva transformação.

Essas mulheres que, historicamente, cumprem com demandas e papeis impostos socialmente perguntam-se quem são, como desejam ser e como não querem mais ser. Esse espaço de indagação é parte importante de um processo que ainda tem muito caminho a percorrer para discutir e combater os entraves do machismo, da dependência, da falta de acesso à educação, da violência sexista, assim como da passividade e da alienação femininas. A denúncia que Dya Kasembe oferece sobre esses lugares impostos às mulheres participa de um processo de reconhecimento do privilégio masculino e promove outras vozes, aquelas dos excluídos do sistema hegemônico e do interesse canônico. É, como o diz a autora, "matéria prima" sobre a qual se possa

6 Nos termos de Amina Mama, com a compreensão de que o psicológico e o social não são territórios separados e que têm raça e gênero como centrais para sua constituição. 
investigar (KASEMBE, 2007, p.188) e que, compartilhada, pode ajudar-nos a ler os espaços instituídos e reproduzidos nas representações sociais das mulheres. Nesse sentido, é evidente que a escrita se revela como potente força de atuação política resistente, mesmo que as oposições binárias de sexo não sejam superadas com tanta facilidade.

\section{REFERÊNCIAS:}

BEAUVOIR, Simone de (2016). O segundo sexo: fatos e mitos/experiências. Tradução Sérgio Milliet. 3.ed. 2 vol. Rio de Janeiro: Nova Fronteira.

BOURDIEU, Pierre (2002). A dominação masculina. Rio de Janeiro: Bertrand Brasil.

FANON, Frantz (2005). Os condenados da terra. Tradução Enilce Albergaria Rocha, Lucy Magalhães. Juiz de Fora: Ed. UFJF.

(2008). Pele negra, máscara branca. Tradução Renato da Silveira.

Salvador: EDUFBA.

KASEMBE, Dya (2010). As mulheres honradas e insubmissas de Angola. 2.ed. Luanda: Editora Mayamba.

(2006). Os amores das Sanzalas. Luanda: Nzila.

(2007). Cartas para maridos temerários. Luanda: Nzila.

KASSEMBE, Dya (2014). Cartas, recados e desabafos. Luanda: Editora Mayamba.

KEHL, Maria Rita (2016). Deslocamentos do feminino: a mulher freudiana na passagem para a modernidade. 2.ed. São Paulo: Boitempo.

MAMA, Amina (s/d). Beyond the Masks. Race, Gender and Subjectivity. London: Routledge.

(2001). "Challeging subjects: gender and power in African contexts". African Sociological Review, 5(2), 63-73.

NASCIMENTO, Elynton Alves do (2009). Estudos do mimetismo em Lycidae 
(Insecta: Coleoptera). São Paulo: Universidade de São Paulo, 2009. 172 f. Tese (Doutorado em Entomologia). Programa de Pós-graduação em Entomologia, Faculdade de Filosofia, Ciências e Letras de Ribeirão Preto, São Paulo.

PAREDES, Margarida (2016). "O livro da paz da mulher angolana: heroínas sem nome". In http://www.esquerda.net/artigo/hero\%C3\%ADnas-semnome Acesso em 05.Jan.2017.

ROCHA, Andrée Crabbré (1965). A Epistolografia em Portugal. Coimbra: Livraria Almedina. p.13.

Rosana Baú Rabello é doutoranda pelo programa de Estudos Comparados de Literaturas de Língua Portuguesa pela USP. Possui graduação em Letras pela UEM (2006) e mestrado em Letras (Literatura Portuguesa) pela USP (2011). Tem experiência na área de Letras, com ênfase em Teoria Literária, atuando principalmente nos seguintes temas: texto dramático, literatura e história. 